\title{
CHARACTERIZATION OF FAMILIAL CAREGIVERS' IN RELATION TO THE KNOWLEDGE ABOUT HYDROCEPHALUS (ABSTRACT)*. DISSERTATION. ARACAJU, 2009.
}

\section{DÉBORA MOURA DA PAIXÃO OLIVEIRA**}

Background: Hydrocephalus is a disease frequently mentioned in literature, but the caregivers' knowledge about the disease is not well assessed.

Purpose: To characterize the caregivers of hydrocephalus patients; identify the fonts of formation to assume activities how to care; to verify caregivers' knowledge about hydrocephalus; to relate the caregiver' knowledge and level of child complications.

Method: Descriptive, exploratory and quantitative study, using a standardized interview technique. The survey was performed with caregivers at Aracaju University Hospital between November 2007 and August 2008.

Results: Fifty-four caregivers answered the interview. The mean age was $27.3 \pm 7$ years, with absolute predominance of females. There was a positive correlation on the number that they had left to work to be caregivers. Twenty-five caregivers $(46.3 \%)$ received information about how to care and $53.7 \%$ learned to take care by themselves. The education level of the caregiver had a significant effect on the knowledge about definition, causes, complications, surgery and the shunt objectives. The knowledge about complications and surgery was significantly bigger in caregivers of children with sequels $(p=0.003)$.

Conclusion: The caregivers received little professional information. The education level of the caregiver had a positive correlation to on increased knowledge. Caregivers of children with sequels were related to on increased knowledge about important aspects on hydrocephalus.

Key words: hydrocephalus, caregiver, family, child. 